\title{
Technology of Perspective Scanning Methods for Realization of 3D Models of Manufacturing Devices
}

Jozef Novak-Marcincin, Jozef Torok, Jozef Barna, Ludmila Novakova-Marcincinova

Faculty of Manufacturing Technologies, Technical University of Kosice, Bayerova 1, 08001 Presov, Slovak Republic

This article provides perspective into creation of virtual 3D models of manufacturing devices and optimization of existing machine tools by using an alternative scanning device and freeware software applications (open source elements). This alternative offers scans of components surfaces that are from the viewpoint of precision and quality comparable with much more expensive devices. Various parts of the paper describe the process of creation of the environment with the use of Kinect scanner device and various software tools. At the end an additional options are provided for using with sensing device.

Keywords: 3D scanner, digitization, Kinect device

\section{Acknowledgements}

Ministry of Education, Science, Research and Sport of SR supported this work, contract VEGA No. 1/0032/12, KEGA No. 002TUKE-4/2012 and ITMS project 26220220125.

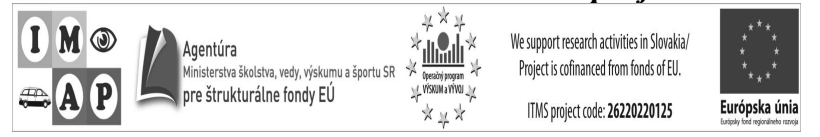

\section{References}

[1] WIKIPEDIA: Kinect. 2012, [cit. 2012-03-20], available at: < http://en.wikipedia.org/wiki/Kinect>.

[2] BORENSTEIN, G.: Making Things See. In: 3D Vision with Kinect, Processing, Arduino, and MakerBot. O'Reilly Media, Inc., 2012. p. 1 - 10, ISBN 978-1449-3277-81.

[3] NEWCOMBE, R. A. et al: KinectFusion: Real-Time Dense Surface Mapping and Tracking. 2011, [cit. 2012-0315], available at: <http://www.pointclouds.org/news/kinectfusion-open-source.html $>$.

[4] MANCTL, P.: Skanect. 2012, [cit. 2012-02-20], available at: < http://manctl.com/products.html>.

[5] IZADI, S. et al: KinectFusion: Real-time 3D reconstruction and interaction using a moving depth camera. 2011, [cit. 2012-03-10], available at: <http://research.microsoft.com/pubs/155416/kinectfusion-uist-comp.pdf>.

[6] BREKELMAN, J.: Brekel Kinect. 2012, [cit. 2012-02-20], available at: <http://manctl.com/products.html>.

[7] SUMA, E. et al.: Flexible Action and Articulated Skeleton Toolkit. 2011, [cit. 2012-03-15], available at: $<$ http://projects.ict.usc.edu/mxr/faast/>.

[8] KINECTHACKS: Finger Movements can be detected by Kinect. 2011, [cit. 2012-02-10], available at: $<$ http://www.kinecthacks.com/finger-movements-can-be-detected-by-kinect/>.

[9] BABKOVA, P., MATEJKA, V.: Laser scanning confocal microscopy as a powerful tool for fracture surface characterization. Manufacturing Technology, Vol. 10, No. 10, 2010, p. 75-78, ISSN 1213-2489.

[10] BARNA, J., FECOVA, V., NOVAK-MARCINCIN, J., TOROK, J.: Utilization of Open Source Application in Area of Augmented Reality Assembling Processes. Manufacturing Technology, Vol. 12, No. 12, 2012, p. 2-7, ISSN 1213-2489.

[11] NOVAK-MARCINCIN, J., BRAZDA, P., JANAK, M., KOCISKO, M.: Application of Virtual Reality Technology in Simulation of Automated Workplaces. Tehnicki Vjesnik - Technical Gazette, Vol. 18, No. 4, 2011 , pp. 577-580, ISSN 1330-3651.

[12] NOVAK-MARCINCIN, J., JANAK, M., BARNA, J., TOROK, J., NOVAKOVA-MARCINCINOVA, L., FECOVA, V.: Verification of a Program for the Control of a Robotic Workcell with the Use of AR. International Journal of Advanced Robotics Systems, Vol. 9, Art. No. 54, 2012, ISSN 1729-8806.

[13] NOVAK-MARCINCIN, J., DOLIAK, M., HLOCH, S., ERGIC, T.: Application of the Virtual Reality Modelling Language to Computer Aided Robot Control System ROANS. Strojarstvo, Vol. 52, No. 2, 2010, p. 227 232, ISSN 0562-1887. 
[14] NOVAK-MARCINCIN, J.: Application of the Virtual Reality Modeling Language for Design of Automated Workplaces. Proceedings of World Academy of Science Engineering and Technology, Vol. 25, 2007, p. 160163, ISSN 1307-6884.

[15] NOVAK-MARCINCIN, J., BARNA, J., JANAK, M., NOVAKOVA-MARCINCINOVA, L., FECOVA, V.: Utilization of Open Source tools in assembling process with application of elements of augmented reality. Proceedings of VRCAI 2011: ACM SIGGRAPH Conference on Virtual-Reality Continuum and its Applications to Industry, 2011, p. 427-430, ISBN 978-145031060-4.

[16] PETRUSKA, P., NOVAK-MARCINCIN, J., DOLIAK, M.: ROANS - intelligent simulation and programming system for robots and automated workcell. Proceedings of the IEEE International Conference on Intelligent Engineering Systems INES, 1997, p. 451-456, ISBN 0-7803-3627-5. 